\title{
Chapas de cimento-madeira com resíduos da indústria madeireira da Região Amazônica
}

Cement-wood particleboards made with waste from the Amazon timber industry

\section{Alcebíades Negrão Macêdo \\ Alberto Alexandre Costa e Souza Bernardo Borges Pompeu Neto}

\section{Resumo}

Alcebíades Negrão Macêdo Instituto de Tecnologia Universidade Federal do Pará Rua Augusto Corrêa, 1 , J urunas Belém - PA - Brasil CEP 66075-110 Tel.: (91) 3201-8062 E-mail: anmacedo@ufpa.br

Alberto Alexandre Costa e nstituto de Universidade Federal do Pará Tel.: (91) 3201-8063 E-mail: costa@ufpa.br

Bernardo Borges Pompeu Neto Instituto de Tecnologia Universidade Federal do Pará Tel.: (91) 3201-7254 E-mail: pompeu@ufpa.br

Recebido em 22/06/11 Aceito em 07/04/12

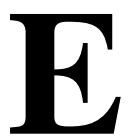

ste estudo teve como objetivo avaliar o emprego do resíduo da indústria madeireira da região da Amazônia brasileira na produção de material compósito cimento-madeira. Foi avaliada a compatibilidade de seis espécies de dicotiledôneas nativas da Amazônia com o cimento CP V ARI por meio da realização de ensaios de compressão axial em corpos de prova cilíndricos. Os resíduos foram utilizados ao natural e submetidos ao tratamento de lavagem em água quente por 2 h. A relação cimento-madeira foi de 3:1, em massa, juntamente com os aditivos aceleradores de pega sulfato de alumínio a 3\% e cloreto de cálcio a 3\% e 5\%. Os resultados dos ensaios de compressão indicaram como potencial de uso os resíduos de três espécies combinado ao tratamento com o acelerador de pega cloreto de cálcio a 5\%. Foram confeccionadas chapas cimento-madeira com resíduos das espécies Cedrela Odorata L. (Cedro), Vochysia máxima Ducke (Quaruba), Hymenaea courbaril L. (Jatobá) e mais a mistura delas. Os resultados dos ensaios das propriedades físicas e mecânicas das chapas mostraram que todas apresentaram características adequadas para a finalidade, e as chapas da espécie cedro apresentaram o melhor desempenho.

Palavras-chave: Compósito cimento-madeira. Dicotiledôneas da Amazônia.

\section{Abstract}

The aim of this study was to to evaluate the use of waste from the timber industry of the Brazilian Amazon Region in the production of wood-cement composites. The compatibility of six Amazon hardwood native species with cement CP V ARI was assessed through axial compression tests in cylindrical specimens. The waste was used was only treated by washing in hot water for two hours. The ratio cement/wood was 3:1 in mass, along with aluminum sulfate curing accelerators at $3 \%$, and calcium chloride curing accelerators at 3\% and 5\%. The results of the axial compression tests indicated the potential use of waste for three species combined with calcium chloride curing accelerator treatment at 5\%. Woodcement particleboards were made with waste of the species Cedrela odorata $L$. (Cedar), Vochysia maximum Ducke (Quaruba), Hymenaea courbaril L. (Jatoba) and a mixture of them. The test results of the physical and mechanical properties of the particleboards showed that all had adequate characteristics for the purpose, and the Cedar species particleboards presented the best performance.

Keywords: Cement-wood composite. Amazon hardwoods. 


\section{Introdução}

As restrições de utilização de materiais ambientalmente inadequados e a necessidade crescente de utilização de resíduos têm levado a indústria à busca de novas alternativas para os produtos oferecidos no mercado. Um exemplo claro dessa tendência é a recente restrição ao uso de fibras de amianto pela indústria. As fibras vegetais, por outro lado, têm sido usadas por milênios pela humanidade, até os dias atuais. Seu uso vem despertando maior interesse em alguns países como uma alternativa de material que poderia viabilizar construções de baixo custo.

As chapas de cimento-madeira, por exemplo, são utilizadas no setor da construção civil na Áustria desde 1920 e na Alemanha desde 1940, e tiveram sua expansão após a II Guerra Mundial, para Austrália, Estados Unidos e países da Ásia. A produção em larga escala surgiu em 1976, na Alemanha, e expandiu-se para os Estados Unidos (wood fiber cement) e México (cement-bonded particleboard). Sua aceitação deve-se ao uso de aglomerante inorgânico, o que lhe confere propriedades superiores às chapas que utilizam resinas sintéticas, garantindo resistência ao fogo, ataque de fungos e cupins, além de isolamento térmico e acústico (LATORRACA, 2000). Outro aspecto importante é o fato de poder utilizar em seu processo de fabricação resíduos da indústria madeireira, agregando valor ao material e reduzindo possíveis impactos ambientais.

A atividade madeireira na região amazônica teve nas últimas décadas uma exploração seletiva e predatória de recursos florestais. Apesar de uma tendência de mudança de paradigmas, o consumo de toras de madeiras no Estado do Pará pela indústria chegou a $11.150 .000 \mathrm{~m}^{3}$ em 2004 segundo Lentini et al. (2005), gerando quantidade significativa de resíduos. Esses resíduos geralmente são depositados a céu aberto ou utilizados, em alguns casos, na geração de energia. O aproveitamento de resíduos de madeira como agregado para fabricação de chapas de cimentomadeira pode ser uma alternativa de material de construção não convencional.

A utilização de resíduos industriais de madeira na fabricação de novos produtos é uma resposta ao meio ambiente, agregando valor ao resíduo e diminuindo a pressão sobre o desmatamento. Sabese que a presença de substâncias químicas presentes na madeira pode retardar ou até impedir a pega da pasta de cimento. No entanto, as pesquisas de Ramírez e Freire (1996), Latorraca (2000), Savastano Junior et al. (2000) têm mostrado a eficiência da aplicação de substâncias químicas chamadas de aceleradores de pega, que chegam a minimizar o efeito adverso desses extrativos. O banho térmico, a mineralização das partículas e a substituição da matriz cimentante por cimentos de baixa alcalinidade são exemplos de tratamentos que podem ser utilizados na produção do compósito (LIMA, 2005).

A grande maioria das pesquisas sobre compósitos cimento-madeira tem-se concentrado em espécies coníferas, o mesmo não ocorrendo com as dicotiledôneas, fato devido à produção comercial destas chapas utilizar coníferas de reflorestamento e pelo efeito mais pronunciado das dicotiledôneas sobre a pega do cimento. Essa carência de estudos sobre compósitos cimento-madeira com dicotiledôneas torna-se mais acentuada quando se trata de dicotiledôneas da região amazônica. Assim, este estudo teve como objetivo avaliar a compatibilidade cimento-madeira de seis dicotiledôneas da região amazônica por meio de ensaios de compressão em corpos de prova cilíndricos e posteriormente avaliar propriedades físico-mecânicas de chapas cimento-madeira confeccionadas com as espécies que apresentaram melhor comportamento nos ensaios de compressão.

\section{Materiais e métodos}

\section{Materiais}

Utilizou-se o cimento Portland CP V-ARI PLUS (alta resistência inicial), NBR 5733 (ABNT, 1991). Sua escolha deveu-se a suas elevadas resistências iniciais, o que favorece a redução do tempo de manipulação de pré-moldados, sendo o mesmo utilizado na indústria de painéis e nas pesquisas desenvolvidas por Moslemi e Pfister (1987), Beraldo et al. (1996, 2002), Zucco (1999), Latorraca (2000) e Batista (2001/2002).

Os resíduos de madeira de seis dicotiledôneas (Figura 1) foram coletados em uma indústria de móveis na cidade de Ananindeua, PA (angelim, cedro, jatobá e tauari) e em uma serraria localizada na cidade de Abaetetuba, também no PA (anani e quaruba). Os nomes vulgares e científicos dessas espécies são apresentados no Quadro 1. Após a homogeneização de cada resíduo, os mesmos foram acondicionados em sacos plásticos e armazenados até sua utilização. Utilizou-se também uma amostra composta da mistura em partes iguais das seis espécies de resíduos. Os resíduos foram identificados no Laboratório de Tecnologia de Produtos Florestais da Universidade Federal Rural da Amazônia (UFRA). 


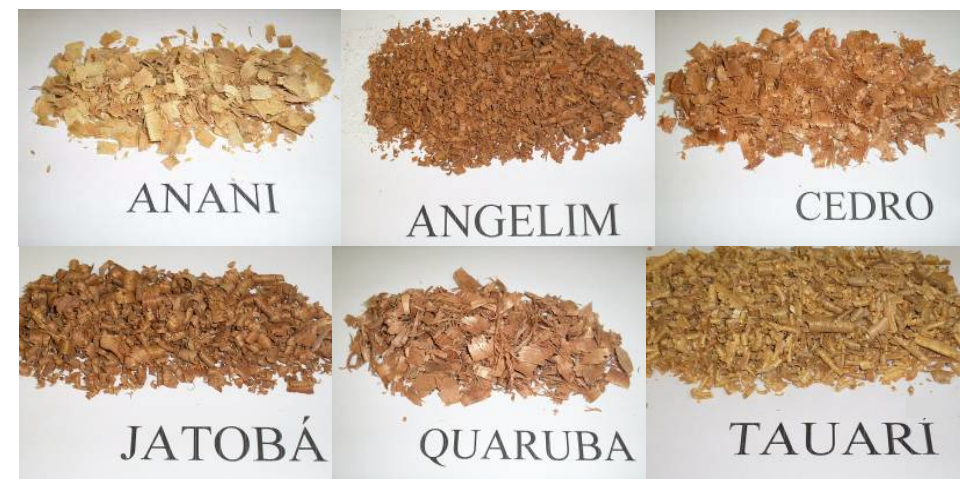

Figura 1 - Resíduos de madeira

\begin{tabular}{|l|l|l|}
\hline \multicolumn{1}{|c|}{ Espécie } & \multicolumn{1}{c|}{ Família } & Nome vulgar \\
\hline Symphonia globulifera L. & Clusiaceae & Anani \\
\hline Dinizia excelsa Ducke & Leguminosaea mimosoidae & Angelim \\
\hline Cedrela odorata L. & Meliaceae & Cedro \\
\hline Hymenaea courbaril L. & Caesalpiniaceaea & Jatobá \\
\hline Vochysia máxima Ducke & Vochysiaceae & Quaruba \\
\hline Couratari oblongifolia Ducke et $R$. Knuth & Lecythidaceae & Tauari \\
\hline
\end{tabular}

Quadro 1 - Relação das espécies coletadas

Os aditivos utilizados para reduzir o tempo de pega da mistura cimento-madeira-água foram os aceleradores de pega, mais especificamente o cloreto de cálcio e o sulfato de alumínio comercial. Esses aditivos foram usados por apresentarem baixo custo e pelo bom desempenho nas pesquisas realizadas por Zhengtian e Moslemi (1985), Teixeira e Guimarães (1989), Zucco (1999), Latorraca e Iwakiri (2001), Beraldo et al. (2002) e Beraldo e Carvalho (2004).

\section{Métodos}

\section{Caracterização dos materiais (cimento e resíduos de madeira)}

As propriedades do cimento utilizado são apresentadas na Tabela 1 e foram determinadas pelo fabricante e confirmadas no Laboratório de Engenharia Civil da UFPA.
Para a realização dos ensaios de análises químicas foram preparadas amostras de resíduo de cada espécie e sua mistura, passando na peneira de 0,60 mm para avaliação dos extrativos solúveis em água quente e fria, visando à determinação de produtos solúveis presentes na madeira. Esses ensaios foram realizados de acordo com as recomendações da Associação Brasileira de Celulose e Papel, Método 4/68, e são apresentados na Tabela 2.

A análise granulométrica do resíduo foi realizada de acordo com a norma NBR 7217 (ABNT, 1987a), por meio de ensaio de peneiramento, realizado em equipamento agitador mecânico de peneiras. As curvas de distribuição apresentadas nas Figuras 2 e 3 mostram a granulometria das seis espécies in natura e lavadas. 
Tabela 1 - Propriedades do cimento Portland de alta resistência inicial CP V-ARI

\begin{tabular}{|c|c|c|c|c|c|c|}
\hline \multicolumn{7}{|c|}{ Ensaios Químicos } \\
\hline \multicolumn{3}{|c|}{ Ensaio } & NBR No & Unidade & Resultados & $\begin{array}{c}\text { Especificação } \\
\text { Norma NBR 5733/91 }\end{array}$ \\
\hline \multicolumn{3}{|c|}{ Perda ao fogo - PF } & $5743 / 89$ & $\%$ & 3,21 & $\leq 4,5$ \\
\hline \multicolumn{3}{|c|}{ Óxido de magnésio - MgO } & NM 11-2/09 & $\%$ & 2,88 & $\leq 6,5$ \\
\hline \multicolumn{3}{|c|}{ Anidro sulfúrico $-\mathrm{SO}_{3}$} & NM 16/04b & $\%$ & 3,60 & $\leq 3,5$ \\
\hline \multicolumn{3}{|c|}{ Resíduo insolúvel - RI } & NM 22/04c & $\%$ & 1,22 & $\leq 1,0$ \\
\hline \multicolumn{3}{|c|}{$\begin{array}{l}\text { Equivalente alcalino em } \mathrm{Na}_{2} \mathrm{O}-(0,658 \times \mathrm{K} 2 \mathrm{O} \%+ \\
\mathrm{Na} 2 \mathrm{O} \%)\end{array}$} & - & $\%$ & 0,88 & Não aplicável \\
\hline \multicolumn{3}{|c|}{ Oxido de cálcio livre - CaO (Livre) } & NM 13/04a & $\%$ & 1,44 & Não aplicável \\
\hline \multicolumn{7}{|c|}{ Ensaios Físicos e Mecânicos } \\
\hline \multicolumn{3}{|c|}{ Ensaio } & NBR N ${ }^{\circ}$ & Unidade & Resultados & $\begin{array}{c}\text { Especificação Norma } \\
\text { NBR 5733/91 }\end{array}$ \\
\hline \multicolumn{3}{|c|}{ Área específica (Blaine) } & NM 76/98b & $\mathrm{m}^{2} / \mathrm{kg}$ & 4.950 & $\geq 3000$ \\
\hline \multicolumn{3}{|c|}{ Massa específica } & NM 23/98a & $\mathrm{g} / \mathrm{cm}^{3}$ & 3,11 & Não aplicável \\
\hline \multicolumn{3}{|c|}{ Densidade aparente } & - & $\mathrm{g} / \mathrm{cm}^{3}$ & 1,07 & Não aplicável \\
\hline \multicolumn{3}{|c|}{ Finura - Resíduo na peneira de 0,075 mm (\#200) } & 11579/91a & $\%$ & 0,42 & $\leq 6$ \\
\hline \multicolumn{3}{|c|}{ Finura - Resíduo na peneira de 0,044 mm (\#325) } & $11579 / 91 a$ & $\%$ & 2,62 & Não aplicável \\
\hline \multicolumn{3}{|c|}{ Água da pasta de consistência normal } & NM 43/03a & Mín & 31,1 & Não aplicável \\
\hline \multicolumn{3}{|c|}{ Início de pega } & NM 65/03b & Mín & 133 & $\geq 60$ \\
\hline \multicolumn{3}{|c|}{ Fim de pega } & NM 65/03b & Mín & 201 & $\leq 720$ \\
\hline \multicolumn{3}{|c|}{ Expansibilidade de Lê Chatelier - a quente } & $11582 / 91 b$ & $\mathrm{~mm}$ & 0 & $\leq 5,0$ \\
\hline \multicolumn{7}{|c|}{ Resistência à Compressão } \\
\hline $\begin{array}{l}\text { Idade } \\
\text { (dias) }\end{array}$ & Mín & Máx & Média & & Desvio & $\begin{array}{c}\text { Especificação } \\
\text { Norma NBR 5733/91 } \\
\end{array}$ \\
\hline 1 & 22,1 & 30,1 & 26,1 & & 2,08 & $\geq 14,0$ \\
\hline 3 & 31,6 & 37,6 & 34,8 & & 1,46 & $\geq 24,0$ \\
\hline 7 & 34,1 & 41,4 & 38,3 & & 1,69 & $\geq 34,0$ \\
\hline 28 & 42,7 & 50,4 & 45,0 & & 1,34 & Não aplicável \\
\hline
\end{tabular}

Tabela 2 - Extrativos totais solúveis em água

\begin{tabular}{l|c|c}
\hline \multirow{2}{*}{ ESPÉCIES } & \% DE PRODUTOS SOLÚVEIS \\
\cline { 2 - 3 } & Em água fria & Em água quente \\
\hline Anani & 6,88 & 4,99 \\
Angelim & 7,74 & 7,40 \\
Cedro & 3,85 & 3,54 \\
Jatobá & 11,15 & 7,06 \\
Mistura & 10,51 & 2,67 \\
Quaruba & 12,40 & 8,10 \\
Tauari & 8,59 & 3,20 \\
\hline
\end{tabular}

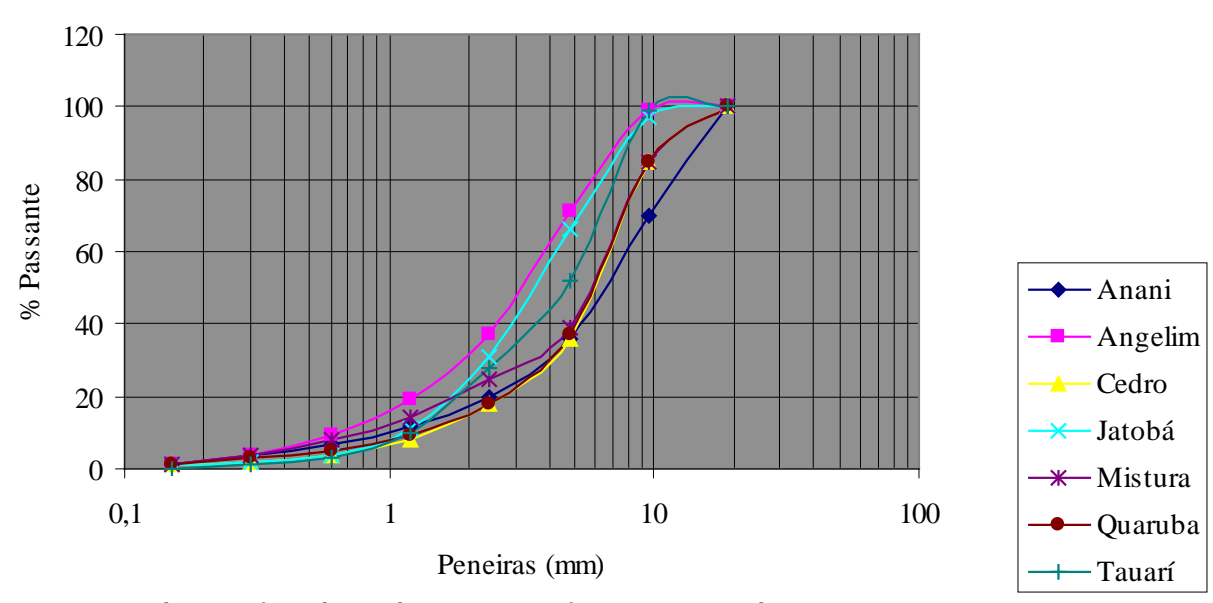

Figura 2 - Curva granulométrica de todas as espécies ao natural 


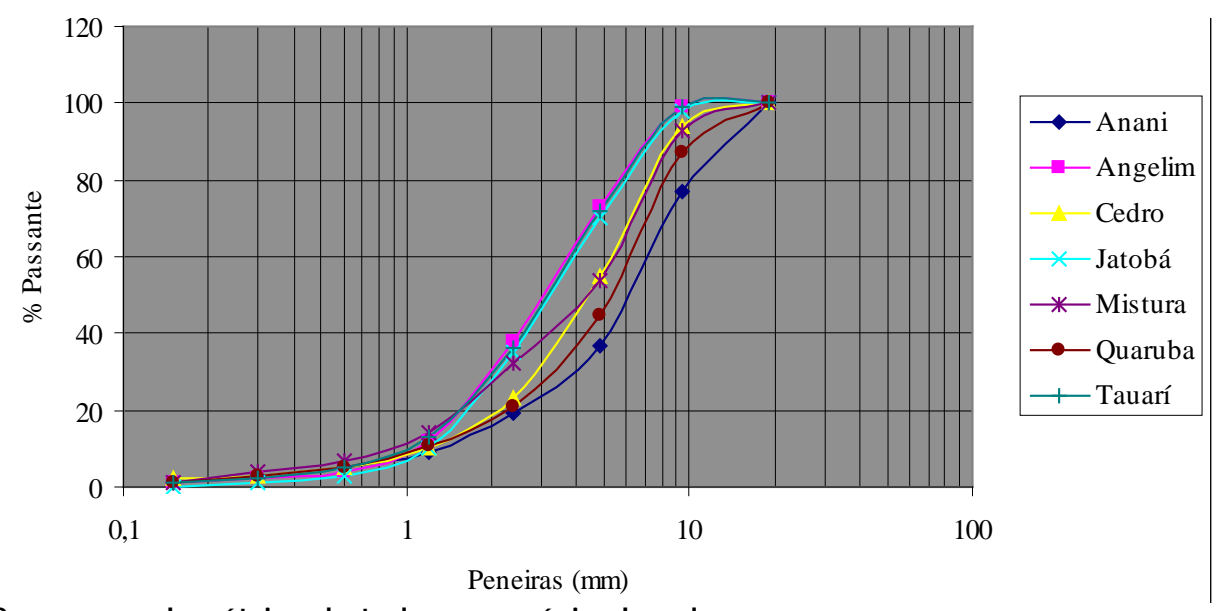

Figura 3 - Curva granulométrica de todas as espécies lavadas

Tabela 3 - Massa unitária do resíduo de madeira estado solto

\begin{tabular}{l|c|c}
\hline \multicolumn{1}{c}{ Espécie } & Natural $\left(\mathbf{k g} / \mathbf{d m}^{3}\right)$ & Lavado $\mathbf{( k g / \mathbf { d m } ^ { 3 } )}$ \\
\hline Anani & 0,086 & 0,083 \\
Angelim & 0,081 & 0,079 \\
Cedro & 0,047 & 0,046 \\
Jatobá & 0,074 & 0,073 \\
Mistura & 0,063 & 0,062 \\
Quaruba & 0,072 & 0,071 \\
Tauari & 0,095 & 0,094 \\
\hline
\end{tabular}

Tabela 4 - Massa específica do resíduo de madeira

\begin{tabular}{l|c|c}
\hline \multicolumn{1}{c|}{ Espécie } & Natural $\mathbf{( g / \mathbf { c m } ^ { 3 } )}$ & Lavada $\mathbf{( g / \mathbf { c m } ^ { 3 } )}$ \\
\hline Anani & 1,15 & 1,01 \\
Angelim & 1,11 & 1,07 \\
Cedro & 1,08 & 0,85 \\
Jatobá & 1,22 & 1,19 \\
Mistura das seis espécies & 1,18 & 1,03 \\
Quaruba & 1,00 & 0,96 \\
Tauari & 1,10 & 1,10 \\
Mistura cedro+jatobá+quaruba & 1,10 & 1,00 \\
\hline
\end{tabular}

Tabela 5 - Teor de umidade do resíduo de madeira

\begin{tabular}{lc}
\hline \multicolumn{1}{c}{ Espécie } & Teor de umidade \% \\
\hline Anani & 14,28 \\
Angelim & 14,18 \\
Cedro & 14,89 \\
Jatobá & 11,23 \\
Mistura das 6 espécies & 13,65 \\
Quaruba & 14,73 \\
Tauari & 12,58 \\
Mistura de 3 espécies & 13,62 \\
\hline
\end{tabular}

A determinação da massa unitária foi realizada de acordo com a norma NBR 7251 (ABNT, 1982), e a determinação da massa específica foi baseada no método empregado por Grandi (1995) com base na NBR 9776 (ABNT, 1987b), Tabelas 3 e 4.

O teor de umidade das amostras foi obtido com base na NBR 9939 (ABNT, 1987c), sendo apresentado na Tabela 5.

\section{Verificação da compatibilidade cimento- madeira}

A verificação da compatibilidade dos resíduos com a matriz cimentante foi realizada por meio da medida de resistência à compressão axial em corpos de prova cilíndricos $(50 \mathrm{~mm}$ x $100 \mathrm{~cm})$. Para a obtenção dos corpos de prova moldou-se 
uma série de quatro amostras para cada espécie de resíduo, para avaliação do fator tratamento (natural e lavado) e fator aditivo sobre o resíduo lavado (cloreto de cálcio a 3\%, sulfato de alumínio a 3\% e cloreto de cálcio a 5\%). As quantidades ensaiadas foram quatro para cada espécie e tratamento, totalizando 140 amostras.

O tratamento por lavagem foi realizado de acordo com Beraldo et al. (1996). Esse tratamento consistiu na imersão do resíduo, por um período de 2 h, em água a $80{ }^{\circ} \mathrm{C}$ na concentração 100 g/litro, e posterior secagem ao ar livre. Optou-se por esse tratamento devido a seu baixo custo e por apresentar possibilidades de eliminar parte dos extrativos solúveis em água sem o uso de substâncias químicas.

Os corpos de prova cilíndricos foram moldados na proporção 3: 1: 0,5 (cimento, madeira e água, ou seja, 1: 0,333: 0,5 em massa). Essa relação foi usada por Moslemi e Pfister (1987), Geimer, Souza e Moslemi (1996), Wolfe e Gjinolli (1997), Latorraca, (2000), Batista (2001/2002) e Beraldo et al. (2002). A relação água-cimento foi igual a 0,6. Utilizou-se como base para moldagem dos corpos de prova, com devidas adaptações, a NBR 7215 (1996). Após 28 dias de cura foram realizados os ensaios de compressão em uma prensa EMIC 2000 $\mathrm{KN}$, com velocidade de carregamento de 0,25 $\pm 0,05 \mathrm{MPa} / \mathrm{s}$ (Figura 4).

\section{Confecção das chapas de cimento-madeira}

Com base nos resultados de resistência à compressão dos corpos de prova cilíndricos optouse pela produção das chapas cimento-madeira com as três espécies de melhor desempenho. As espécies selecionadas foram o cedro, o jatobá e a quaruba, com maior resistência mecânica à compressão. Os resíduos de madeira foram lavados em água a $80{ }^{\circ} \mathrm{C}$ por $2 \mathrm{~h}$, e o aditivo utilizado foi o $\mathrm{CaCl}_{2}$ a $5 \%$ em relação à massa de cimento.

As chapas com resíduos das três espécies selecionadas e mais a mistura delas foram confeccionadas utilizando-se moldes metálicos para produção de cinco unidades simultaneamente, compostos de duas chapas de aço de dimensões $58,60 \mathrm{~cm} \mathrm{x} \mathrm{43,00} \mathrm{cm} \mathrm{e} \mathrm{espessura} \mathrm{de} \mathrm{2,5} \mathrm{cm} \mathrm{(1”),}$ uma servindo de fundo e a outra de tampa, e quatro chapas divisórias com as mesmas dimensões e espessura de $0,625 \mathrm{~cm}$ (1/4”), com furos nas extremidades para passagem de parafusos (Figuras 5 e 6).

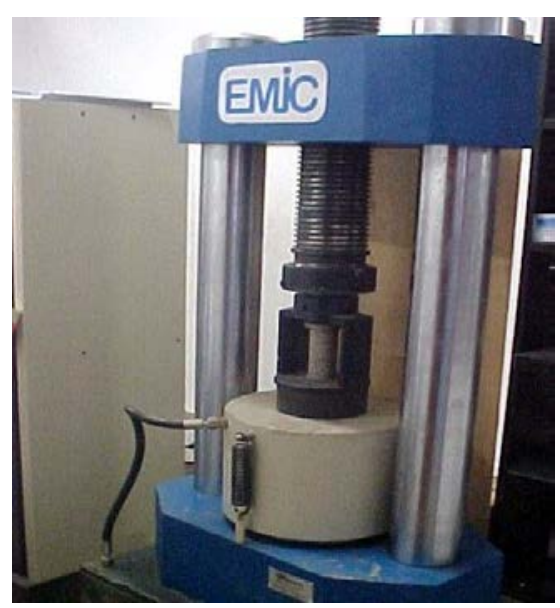

Figura 4 - Ensaios de compressão axial

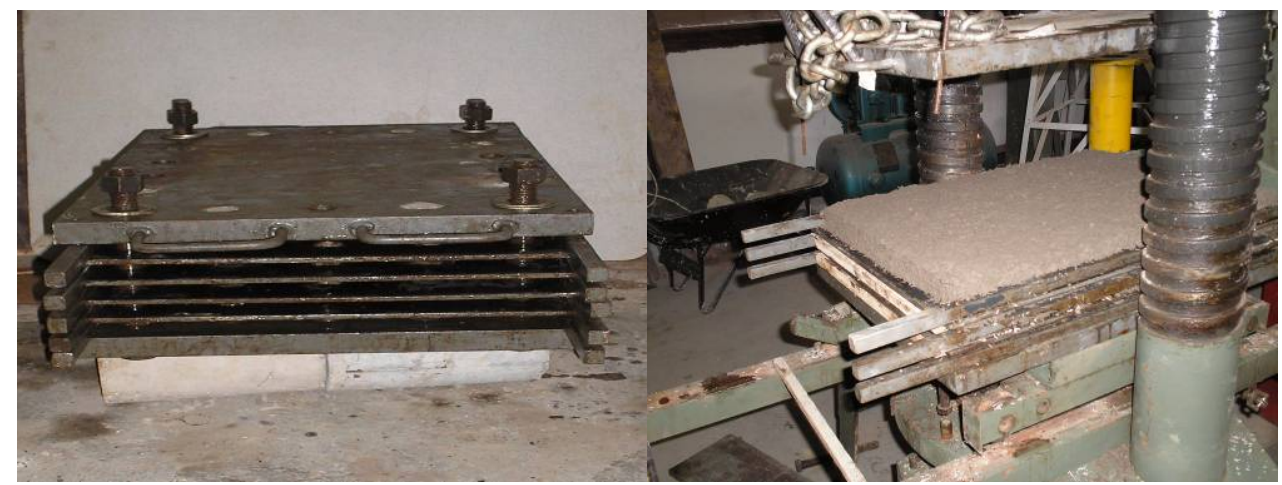

Figura 5 - Molde metálico e formação do colchão de cimento-madeira

136 Macêdo, A. N.; Costa e Souza, A. A.; Pompeu Neto, B. B. 


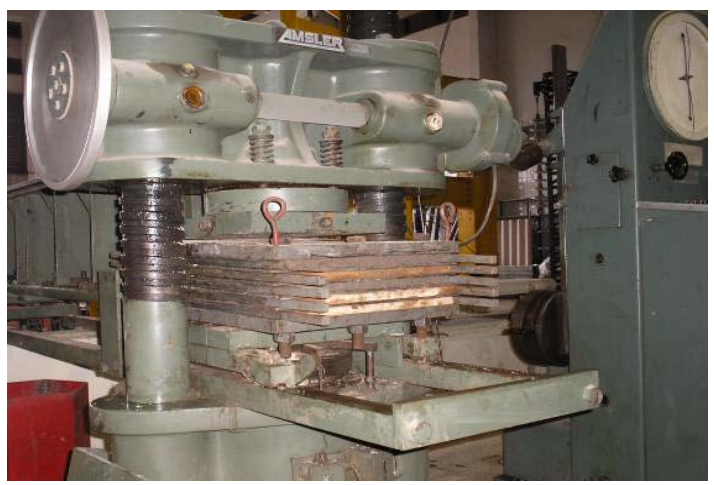

Figura 6 - Aplicação de pressão no molde

Para a manufatura das chapas as quantidades de materiais foram determinadas experimentalmente, com a relação cimento-madeira 3:1 (em massa), de forma a proporcionar uma massa específica similar para todas as chapas. A quantidade de material foi sugestionada pelos ensaios preliminares, realizados sem controle de adensamento, de modo a proporcionar um colchão com altura superior à final da chapa. A pressão aplicada foi de 40 $\mathrm{kg} / \mathrm{cm}^{2}$, mantida até que o colchão atingisse a espessura desejada. A pressão de $40 \mathrm{~kg} / \mathrm{cm}^{2}$ é a mesma utilizada para fabricação de chapas aglomeradas com adesivos sintéticos e adotada por Latorraca (2000), Mendes et al. (2004) e Okino et al. (2004). Após atingir a pressão desejada, foi realizada a fixação chapas de aço por meio de parafusos para que a pressão do sistema fosse mantida por $24 \mathrm{~h}$. Decorridas $24 \mathrm{~h}$, as chapas foram retiradas e acondicionadas numa câmara com temperatura de $20 \pm 3{ }^{\circ} \mathrm{C}$ e $65 \pm 5 \%$ de umidade por mais 27 dias, até completar os 28 dias de cura.

\section{Propriedades físicas e mecânicas das chapas de cimento-madeira}

\section{Propriedades físicas (densidade, umidade, inchamento e absorção)}

Os ensaios para a determinação das características físicas e mecânicas das chapas de cimento-madeira foram realizados com base nas normas europeias. A determinação da densidade seguiu a EN 323 (EUROPEAN..., 1993e), que especifica corpos de prova de dimensões $50 \times 50 \pm 1 \mathrm{~mm}$ de aresta condicionados, até constância de massa, numa atmosfera com umidade relativa de $65 \pm 5 \%$ e uma temperatura de $20 \pm 2{ }^{\circ} \mathrm{C}$. Foram ensaiadas 8 amostras para cada espécie, 4 obedecendo à orientação A e 4 à orientação B (Figura 7). O teor de umidade das chapas foi obtido com base nas recomendações da EN 322 (EUROPEAN..., 1993d). A quantidade de água contida é eliminada por secagem em estufa até massa constante à temperatura de $103 \pm 2{ }^{\circ} \mathrm{C}$. $\mathrm{O}$ inchamento em espessura foi medido entre o estado seco e após a imersão por $24 \mathrm{~h}$, seguindo as recomendações da EN 317 (EUROPEAN..., 1993b). De maneira similar a determinação do índice de absorção também seguiu as recomendações da EN 317.

A retirada dos corpos de prova das chapas seguiu as recomendações da norma ASTM (AMERICAN..., 1996), Figura 7. As orientações A e B indicadas para a retirada dos corpos de prova (Figura 7) são adotadas para levarem-se em consideração possíveis distorções na orientação das fibras e/ou variações de pressão na moldagem das chapas.

\section{Propriedades mecânicas}

Os ensaios de flexão estática têm por objetivo a determinação do módulo de elasticidade (MOE) e do módulo de ruptura (MOR), e foram realizados com base na EN 310 (EUROPEAN..., 1993a). Neste trabalho foram utilizadas 12 amostras de cada espécie, com dimensões nominais de $16 \mathrm{~mm}$ de espessura, $370 \mathrm{~mm}$ de comprimento e $50 \mathrm{~mm}$ de largura. Todos os ensaios foram realizados em uma máquina universal EMIC de $5 \mathrm{kN}$ de capacidade, disponível no Laboratório de Engenharia Mecânica da UFPA (Figura 8).

As 12 amostras utilizadas para a determinação do MOR e MOE para cada espécie foram retiradas de acordo com as orientações definidas na Figura 7 , ou seja, 6 para orientação A (longitudinal) e 6 para orientação B (transversal).

O ensaio de tração perpendicular ou adesão interna (Figura 9) foi realizado em 8 amostras, de acordo com a norma EN 319 (EUROPEAN..., 1993c), que prescreve o uso de corpos de prova quadrados, com $50 \pm 1 \mathrm{~mm}$ de aresta. Foram colados nas duas faces dos corpos de prova suportes de metal para que as amostras pudessem ser solicitadas perpendicularmente. O adesivo utilizado para a fixação das chapas foi uma adesivo à base de epóxi. 


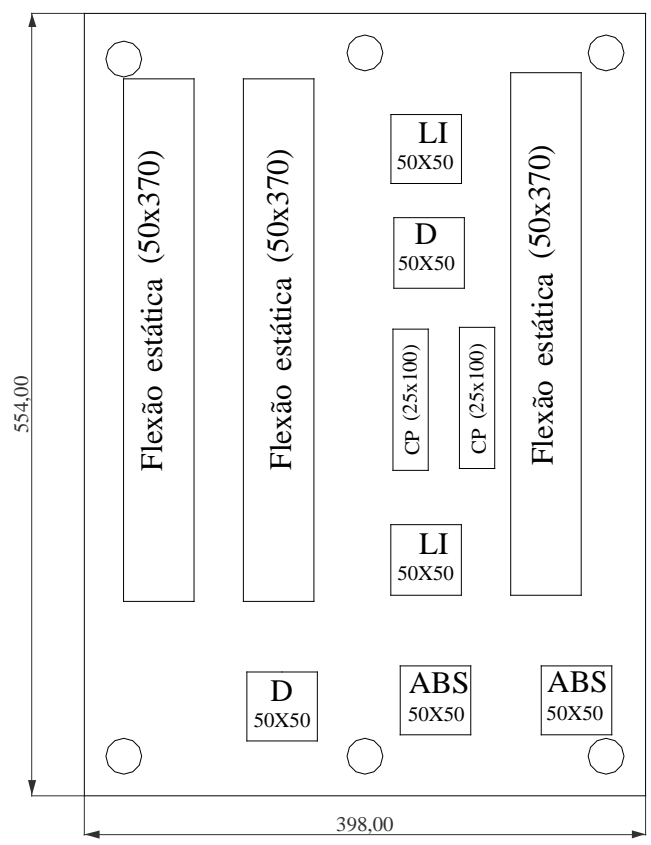

(a) Orientação A

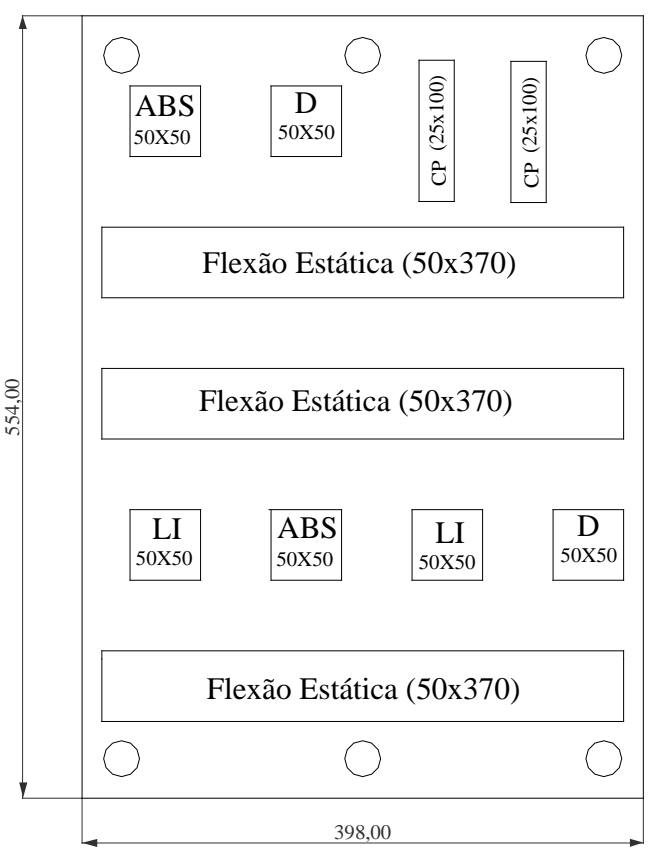

(b) Orientação B

Figura 7 - Forma de extração dos corpos de prova nas chapas (mm)

Nota: Legenda:

ABS: absorção;

CP: compressão paralela;

D: densidade; e

LI: ligação interna.

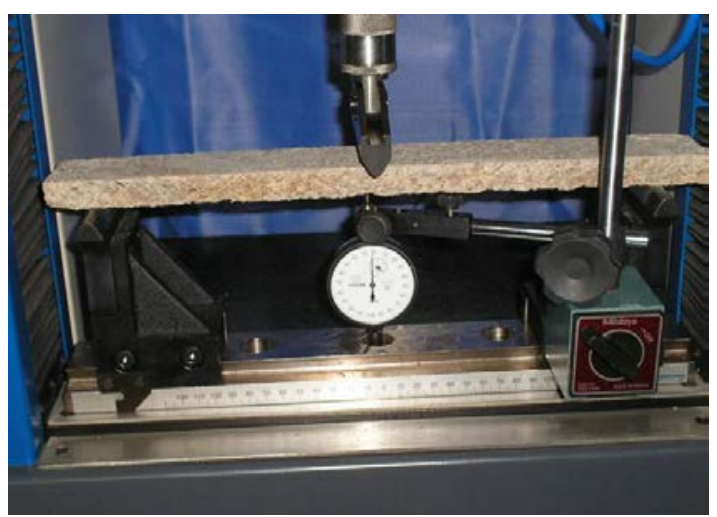

Figura 8 - Ensaio de flexão estática

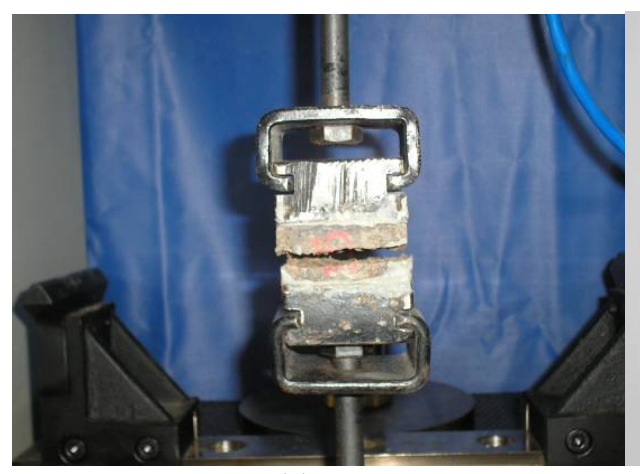

(a)

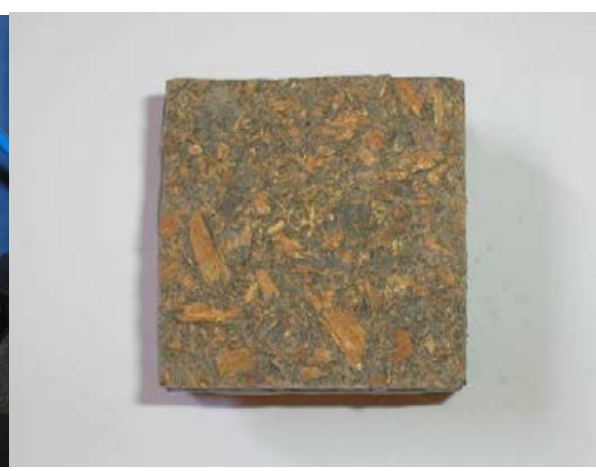

(b)

Figura 9 - Ensaios de tração perpendicular: (a) ensaio e (b) corpo de prova rompido 
Os ensaios de compressão paralela à superfície da chapa foram realizados com as condições de estocagem em câmara úmida.

\section{Resultados obtidos e análises}

\section{Verificação da compatibilidade dos} resíduos para escolha das espécies

Os resultados dos ensaios de resistência à compressão aos 28 dias são apresentados na Tabela 6 e na Figura 10. Todos os resultados foram submetidos à análise estatística ANOVA, ao nível de 95\% de probabilidade, para verificar diferenças estatísticas entre os mesmos. As médias foram comparadas pelo teste Fisher-Snedecor ao nível de significância de $5 \%$ todas as vezes que a hipótese de nulidade foi rejeitada.

Através da Tabela 6 e da Figura 10 podem ser observadas as baixas resistências à compressão axial das espécies quando utilizadas ao natural, demonstrando a interferência acentuada de extrativos, que influenciam no processo de hidratação do cimento. Somente as espécies cedro, quaruba, tauari e a mistura atingiram valores de resistência superiores a 2,0 MPa, referência mínima no trabalho de Zucco (1999).

Tabela 6 - Resultados dos ensaios de resistência à compressão nos corpos de prova cilíndricos

\begin{tabular}{|c|c|c|c|c|c|c|c|c|c|}
\hline \multirow{2}{*}{ Espécie } & \multirow{2}{*}{ Tratamento } & \multicolumn{4}{|c|}{ Resistência CPs (MPa) } & \multirow{2}{*}{$\begin{array}{l}\text { Média } \\
\text { (MPa) }\end{array}$} & \multirow{2}{*}{ Variância } & \multirow{2}{*}{$\begin{array}{c}\text { Desv. } \\
\text { padrão }\end{array}$} & \multirow{2}{*}{$\begin{array}{l}\text { Coef. } \\
\text { var. }\end{array}$} \\
\hline & & 1 & 2 & 3 & 4 & & & & \\
\hline \multirow{5}{*}{ Anani } & Natural & 1,85 & 1,72 & 1,85 & 1,72 & 1,79 & 0,006 & 0,075 & 0,042 \\
\hline & Lavado & 4,08 & 4,08 & 3,70 & 3,85 & 3,93 & 0,035 & 0,186 & 0,047 \\
\hline & $3 \%$ sulfato & 6,71 & 7,17 & 7,21 & 6,48 & 6,89 & 0,127 & 0,356 & 0,052 \\
\hline & $3 \%$ cloreto & 4,54 & 5,02 & 4,59 & 5,00 & 4,79 & 0,066 & 0,258 & 0,054 \\
\hline & $5 \%$ cloreto & 8,51 & 8,70 & 8,86 & 9,08 & 8,79 & 0,058 & 0,242 & 0,028 \\
\hline \multirow{5}{*}{ Angelim } & Natural & 0,57 & 0,60 & 0,59 & 0,63 & 0,60 & 0,001 & 0,025 & 0,042 \\
\hline & Lavado & 0,97 & 0,95 & 0,93 & 0,93 & 0,95 & 0,000 & 0,019 & 0,020 \\
\hline & $3 \%$ sulfato & 5,00 & 5,15 & 4,66 & 4,69 & 4,88 & 0,057 & 0,239 & 0,049 \\
\hline & $3 \%$ cloreto & 10,83 & 12,06 & 10,93 & 12,02 & 11,46 & 0,450 & 0,671 & 0,059 \\
\hline & $5 \%$ cloreto & 5,55 & 5,65 & 6,08 & 6,06 & 5,84 & 0,075 & 0,275 & 0,047 \\
\hline \multirow{5}{*}{ Cedro } & Natural & 2,17 & 2,17 & 2,29 & 2,14 & 2,19 & 0,004 & 0,067 & 0,030 \\
\hline & Lavado & 2,10 & 2,36 & 2,44 & 2,29 & 2,30 & 0,021 & 0,145 & 0,063 \\
\hline & $3 \%$ sulfato & 2,97 & 2,98 & 2,59 & 2,59 & 2,78 & 0,049 & 0,222 & 0,080 \\
\hline & $3 \%$ cloreto & 9,61 & 8,89 & 9,08 & 8,77 & 9,09 & 0,138 & 0,371 & 0,041 \\
\hline & $5 \%$ cloreto & 9,73 & 9,84 & 9,84 & 10,18 & 9,90 & 0,038 & 0,195 & 0,020 \\
\hline \multirow{5}{*}{ Jatobá } & Natural & 1,12 & 1,07 & 1,02 & 1,07 & 1,07 & 0,002 & 0,041 & 0,038 \\
\hline & Lavado & 1,26 & 1,32 & 1,32 & 1,36 & 1,32 & 0,002 & 0,041 & 0,031 \\
\hline & $3 \%$ sulfato & 6,64 & 7,02 & 7,25 & 7,02 & 6,98 & 0,064 & 0,253 & 0,036 \\
\hline & $3 \%$ cloreto & 12,28 & 12,59 & 11,85 & 11,91 & 12,16 & 0,119 & 0,345 & 0,028 \\
\hline & $5 \%$ cloreto & 19,53 & 21,59 & 19,88 & 21,51 & 20,63 & 1,156 & 1,075 & 0,052 \\
\hline \multirow{5}{*}{ Tauari } & Natural & 3,47 & 3,59 & 3,47 & 3,39 & 3,48 & 0,007 & 0,082 & 0,024 \\
\hline & Lavado & 3,78 & 3,59 & 3,62 & 3,43 & 3,61 & 0,021 & 0,143 & 0,040 \\
\hline & $3 \%$ sulfato & 4,81 & 5,22 & 4,81 & 5,30 & 5,04 & 0,069 & 0,262 & 0,052 \\
\hline & $3 \%$ cloreto & 6,75 & 7,35 & 7,10 & 7,40 & 7,15 & 0,088 & 0,297 & 0,042 \\
\hline & $5 \%$ cloreto & 7,21 & 6,57 & 7,21 & 6,51 & 6,88 & 0,150 & 0,388 & 0,056 \\
\hline \multirow{5}{*}{ Quaruba } & Natural & 2,63 & 2,75 & 2,71 & 2,63 & 2,68 & 0,004 & 0,060 & 0,022 \\
\hline & Lavado & 2,98 & 2,71 & 2,75 & 2,82 & 2,82 & 0,014 & 0,119 & 0,042 \\
\hline & $3 \%$ sulfato & 2,67 & 2,78 & 2,48 & 2,59 & 2,63 & 0,016 & 0,127 & 0,048 \\
\hline & $3 \%$ cloreto & 13,85 & 13,62 & 13,16 & 13,18 & 13,45 & 0,115 & 0,340 & 0,025 \\
\hline & $5 \%$ cloreto & 14,62 & 15,34 & 14,09 & 15,28 & 14,83 & 0,351 & 0,593 & 0,040 \\
\hline \multirow{5}{*}{ Mistura } & Natural & 2,09 & 2,04 & 1,98 & 1,98 & 2,02 & 0,003 & 0,053 & 0,026 \\
\hline & Lavado & 3,43 & 3,13 & 3,32 & 3,12 & 3,25 & 0,023 & 0,151 & 0,047 \\
\hline & $3 \%$ sulfato & 2,94 & 3,20 & 3,01 & 2,98 & 3,03 & 0,013 & 0,115 & 0,038 \\
\hline & $3 \%$ cloreto & 9,23 & 8,47 & 8,28 & 9,08 & 8,77 & 0,213 & 0,461 & 0,053 \\
\hline & $5 \%$ cloreto & 7,78 & 7,79 & 8,01 & 8,65 & 8,06 & 0,167 & 0,409 & 0,051 \\
\hline
\end{tabular}




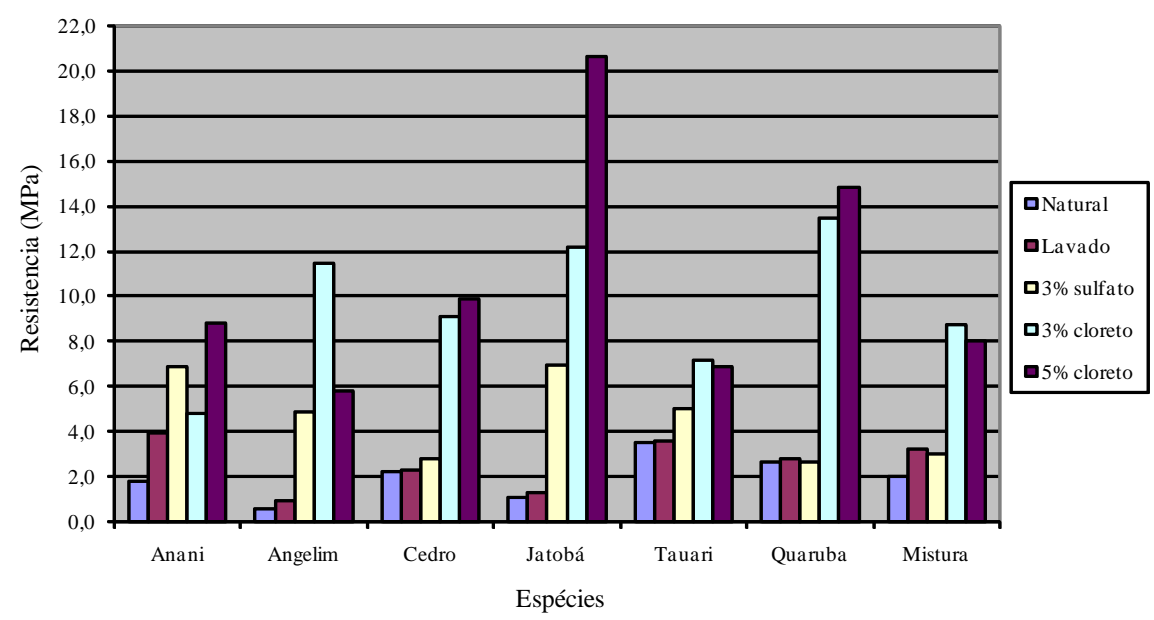

Figura 10 - Resultados dos valores médios dos ensaios de compressão axial aos 28 dias

O ambiente alcalino do cimento pode ter contribuído para a conversão parcial da hemicelulose e polímeros de açúcares, provocando problemas na hidratação, o que implica uma diminuição da resistência do compósito. Essas espécies, de um modo geral, apresentam incompatibilidade maior que as coníferas, devido à maior quantidade de hemicelulose solúvel, que pode ser dissolvida em soluções alcalinas e degradadas em açúcares simples, interferindo no processo de hidratação do cimento.

A lavagem dos resíduos em água quente por 2 h apresentou efeito diferenciado nas amostras, colaborando de forma discreta nos resultados de algumas espécies e demonstrando a influência da presença de substâncias não solúveis em água fria e quente que interferem na hidratação da pasta de cimento.

Ainda na Tabela 6 e na Figura 10 podem ser observados os resultados dos ensaios de compressão axial e a influência do uso dos aditivos químicos cloreto de cálcio e sulfato de alumínio. Os aditivos foram testados inicialmente com a concentração de 3\%, de acordo com a metodologia apresentada. O desempenho de aditivo sulfato de alumínio só foi superior na espécie anani; para as demais houve superioridade do cloreto de cálcio, que foi adotado para testes com 5\% de teor. A superioridade do $\mathrm{CaCl}_{2}$ sobre o $\mathrm{Al}_{2}\left(\mathrm{SO}_{3}\right)_{4}$ foi também verificada por Pimentel (2000) e Zucco (1999). A variação na concentração do cloreto de cálcio de 3\% para 5\% mostrou uma melhora substancial apenas para as espécies anani e jatobá, sendo seu efeito sobre as demais discreto.

\section{Características físicas das chapas de cimento-madeira}

Para cada uma das propriedades físicas estudadas foi realizada a análise de variância ANOVA do fator espécie, que estão resumidas nas Tabelas 7 a 11.

Os resultados dos ensaios de densidade das chapas são apresentados na Tabela 7 e Figura 11. 
Tabela 7 - Resultados de densidade

\begin{tabular}{c|c|c|c|c}
\hline \multirow{2}{*}{ Corpo de prova } & \multicolumn{4}{|c}{ Densidade $\left(\mathbf{k g} / \mathbf{m}^{3}\right)$} \\
\cline { 2 - 5 } & Cedro & Jatobá & Quaruba & Mistura \\
\hline 1 (A) & 1.331 & 1.620 & 1.461 & 1.497 \\
2 (A) & 1.333 & 1.513 & 1.416 & 1.482 \\
3 (A) & 1.300 & 1.556 & 1.454 & 1.295 \\
4 (A) & 1.358 & 1.598 & 1.479 & 1.342 \\
1 (B) & 1.291 & 1.556 & 1.367 & 1.338 \\
2 (B) & 1.306 & 1.519 & 1.410 & 1.461 \\
3 (B) & 1.306 & 1.533 & 1.398 & 1.331 \\
4 (B) & 1.415 & 1.562 & 1.481 & 1.496 \\
Média & 1.330 & 1.557 & 1.433 & 1.405 \\
Variância & 1.656 & 1.376 & 1.721 & 7.406 \\
Desv. pad. & 40,69 & 37,10 & 41,48 & 86,06 \\
Coef. var. & 0,03 & 0,02 & 0,03 & 0,06 \\
\hline
\end{tabular}

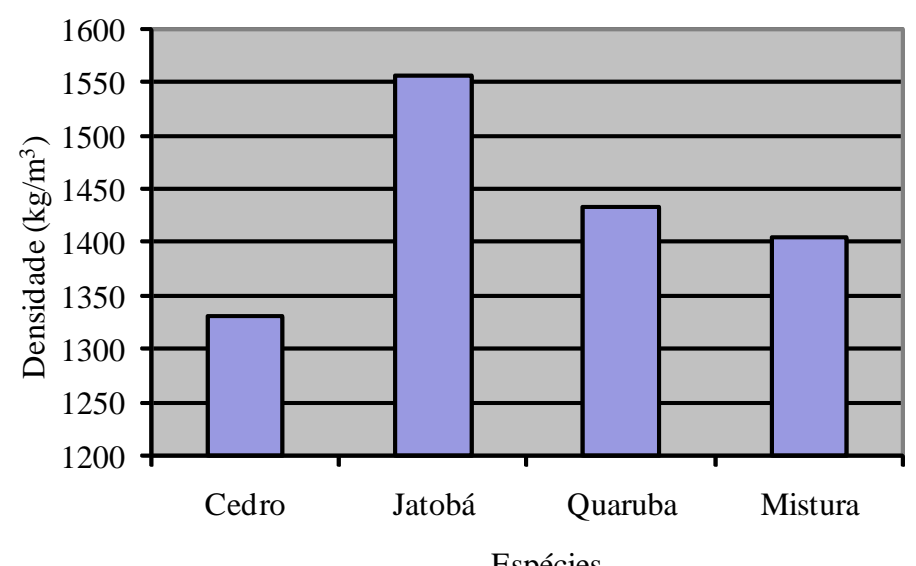

Figura 11 - Médias das densidades das chapas

Espécies

Os ensaios foram realizados com as condições de estocagem em câmara úmida. Analisando os resultados de densidade (Tabela 7 e Figura 11), foi verificada a diferença entre os resultados das espécies. As chapas confeccionadas com os resíduos de jatobá apresentaram a maior densidade em virtude de esse resíduo apresentar maior massa específica, o que leva a pensar que suas fibras estejam mais compactadas.

Pode-se afirmar que a massa específica do resíduo interfere diretamente na densidade da chapa. A densidade também pode variar em chapas de uma mesma espécie, variando a quantidade de material, para uma mesma pressão aplicada, ou seja, quanto maior for a quantidade de material utilizada para a fabricação de uma chapa, maior será a densidade e maior será a razão de compactação. O volume de cimento neste caso tem a maior influência no peso da chapa. Os resultados encontrados estão dentro dos valores utilizados pela Federação da Indústria de Fabricantes de Chapas (WOOD..., 2004), que estabelece a densidade mínima de $1.100 \mathrm{~kg} / \mathrm{m}^{3}$.
O teor de umidade foi determinado para amostras recém-tiradas da câmara úmida (C) e para amostras seca ao ar (S) (Tabela 8 e Figura 12).

A resistência mecânica da chapa de cimentomadeira é influenciada por seu teor de umidade. Quanto maior a umidade, menor será a resistência mecânica. Esse fato foi verificado por Savastano Junior (1992) durante o estudo da interface fibramatriz. A perda de resistência mecânica no compósito, com o aumento da umidade, dá-se pela variação dimensional da fibra, que é responsável por seu descolamento, diminuindo a aderência fibra-matriz.

O compósito cimento-madeira é um material higroscópico e tem seu teor de umidade condicionado à umidade relativa do local de aplicação. Os corpos de prova foram retirados de uma câmara úmida, e os valores dos ensaios refletem as condições de armazenagem. Para os fabricantes de chapas, a umidade de equilíbrio fica entre $5 \%$ e $14 \%$, mas na prática pode ser superior a 15\% (WOOD..., 2004). 
Devido à porosidade da chapa e às condições de estocagem (câmara úmida), as chapas apresentaram teor de umidade superior em relação às secas ao ar (Tabela 8 e Figura 12). A espécie jatobá apresentou o maior teor de umidade $(18,59 \%)$ para as mesmas condições de estocagem, o que pode ser explicado pela maior porosidade da chapa, decorrente de um menor fator de compactação, que influenciou nos resultados de MOE e MOR à flexão.

Os resultados de inchamento das chapas são apresentados na Tabela 9 e Figura 13.

Tabela 8 - Resultados de teor de umidade

\begin{tabular}{c|c|c|c|c|c|c|c|c}
\hline \multirow{2}{*}{ Corpo de prova } & \multicolumn{7}{|c}{ Teor de umidade (\%) } \\
\cline { 2 - 9 } & \multicolumn{2}{|c|}{ Cedro } & \multicolumn{2}{c}{ Jatobá } & \multicolumn{2}{c}{ Quaruba } & \multicolumn{2}{c}{ Mistura } \\
\cline { 2 - 9 } & C & S & C & S & C & S & C & S \\
\hline 1 (A) & 17,3 & 7,7 & 20,8 & 12,5 & 16,4 & 7,3 & 16,1 & 7,2 \\
2 (A) & 17,7 & 7,8 & 21,3 & 8,5 & 17,7 & 7,8 & 14,8 & 9,3 \\
3 (A) & 17,4 & 8,7 & 18,4 & 8,2 & 13,8 & 6,9 & 17,4 & 10,9 \\
4 (A) & 15,6 & 11,1 & 17,3 & 7,7 & 14,8 & 6,6 & 18,8 & 8,3 \\
1 (B) & 19,6 & 13,0 & 17,7 & 9,8 & 14,8 & 9,3 & 20,0 & 10,2 \\
2 (B) & 16,3 & 11,6 & 18,4 & 10,2 & 13,8 & 8,6 & 16,1 & 8,9 \\
3 (B) & 14,3 & 12,2 & 17,7 & 9,8 & 14,0 & 12,0 & 18,4 & 10,2 \\
4 (B) & 17,3 & 9,6 & 17,3 & 9,6 & 17,0 & 7,6 & 17,3 & 9,6 \\
Média & 16,9 & 10,2 & 18,6 & 9,5 & 15,3 & 8,3 & 17,3 & 9,3 \\
Variância & 2,5 & 4,2 & 2,5 & 2,2 & 2,3 & 3,1 & 2,8 & 1,4 \\
Desv. pad. & 1,5 & 1,9 & 1,5 & 1,4 & 1,4 & 1,6 & 1,6 & 1,1 \\
Coef. var. & 0,1 & 0,2 & 0,1 & 0,1 & 0,1 & 0,2 & 0,1 & 0,1 \\
\hline
\end{tabular}

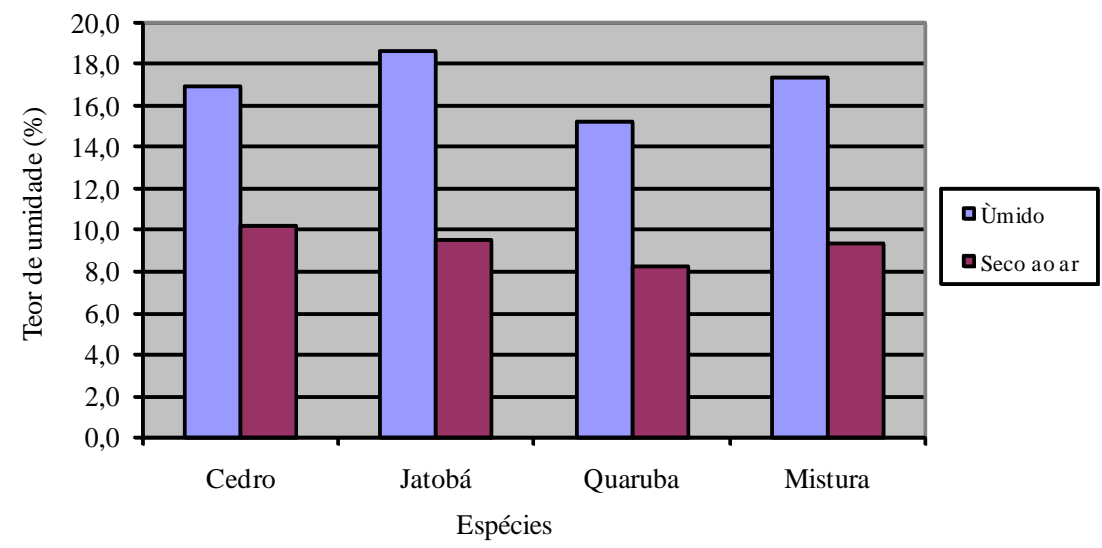

Figura 12 - Médias do teor de umidade das chapas

Tabela 9 - Resultados de inchamento em espessura

\begin{tabular}{c|c|c|c|c}
\hline \multirow{2}{*}{ Corpo de prova } & \multicolumn{4}{|c}{ Inchamento (\%) } \\
\cline { 2 - 5 } & Cedro & Jatobá & Quaruba & Mistura \\
\hline 1 (A) & 0,71 & 0,32 & 0,19 & 0,71 \\
2 (A) & 0,47 & 0,32 & 0,70 & 1,09 \\
3 (A) & 0,78 & 0,92 & 0,22 & 1,59 \\
4 (A) & 0,29 & 0,56 & 0,39 & 0,04 \\
1 (B) & 0,91 & 1,13 & 0,60 & 0,58 \\
2 (B) & 0,78 & 0,40 & 0,86 & 0,53 \\
3 (B) & 0,55 & 0,27 & 0,42 & 1,19 \\
4 (B) & 1,24 & 0,23 & 1,38 & 1,09 \\
Média & 0,72 & 0,52 & 0,60 & 0,85 \\
Variância & 0,08 & 0,11 & 0,15 & 0,23 \\
Desv. pad. & 0,29 & 0,33 & 0,39 & 0,48 \\
Coef. var. & 0,41 & 0,64 & 0,66 & 0,57 \\
\hline
\end{tabular}

142 Macêdo, A. N.; Costa e Souza, A. A.; Pompeu Neto, B. B. 


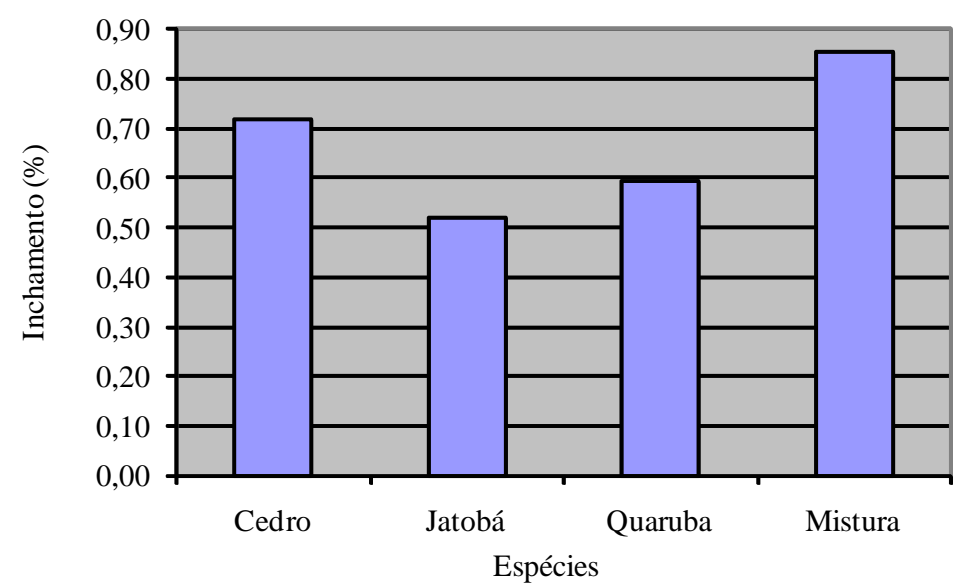

Figura 13 - Médias do inchamento em espessura das chapas

Os resultados dos ensaios de inchamento (Tabela 9 e Figura 13) foram medidos entre o estado seco e após a imersão em água por $24 \mathrm{~h}$. As menores médias foram obtidas para as chapas de jatobá e quaruba. Para Latorraca (2000), essa propriedade física é pouco influenciada pelas outras variáveis em função do ambiente de enclausuramento das partículas de madeira, oferecido pela matriz de cimento. As médias de inchamento de todas as espécies ficaram abaixo das médias exigidas pele fabricante de chapas Bison Wood-Cement Board (1978), que é de 1,8\%.

Os resultados de absorção de água são apresentados na Tabela 10 e Figura 14.

Para a absorção de água em 24 h (Tabela 10 e Figura 14), as medidas dos corpos de prova foram feitas entre o estado seco e o saturado. A variação granulométrica e o teor de fibras vegetais provocam efeito significativo na absorção de água. Compósitos com maior quantidade de finos, e teor de fibras, proporcionam absorções maiores, relacionadas a uma maior área específica das partículas, aumentando, assim, a retenção de água.
Para o fabricante de chapas de cimento-madeira Cetris, o valor máximo de absorção de água para esse material é de 32\%. As espécies estudadas apresentaram médias estatisticamente iguais e encontram-se dentro dos valores aceitáveis, sendo a maior absorção em número relativo a da mistura das espécies (30,97\%) e da quaruba (30,68\%), inferiores ao obtido por Latorraca (2000) para o Ecalyptus spp, que foi de 35,19\%. Como todas as amostras apresentaram semelhanças granulométricas, pode-se atribuir essa diferença de absorção na estrutura das fibras presentes nessas amostras.

\section{Propriedades mecânicas das chapas de cimento-madeira}

As Tabelas 11 a 13 e as Figuras 15 a 18 apresentam os resultados dos ensaios mecânicos de flexão estática, tração perpendicular e compressão paralela.

Tabela 10 - Resultados de absorção de água após $\mathbf{2 4}$ h

\begin{tabular}{c|c|c|c|c}
\hline \multirow{2}{*}{ Corpo de prova } & \multicolumn{4}{|c}{ Absorção (\%) } \\
\cline { 2 - 5 } & Cedro & Jatobá & Quaruba & Mistura \\
\hline 1 (A) & 23,2 & 32,0 & 19,6 & 34,0 \\
2 (A) & 28,0 & 29,2 & 44,0 & 34,0 \\
3 (A) & 25,5 & 27,3 & 37,3 & 31,3 \\
4 (A) & 25,9 & 24,5 & 35,2 & 33,3 \\
1 (B) & 26,7 & 22,9 & 26,4 & 29,2 \\
2(B) & 28,1 & 28,0 & 25,9 & 29,4 \\
3 (B) & 28,6 & 25,0 & 25,0 & 30,6 \\
4 (B) & 28,0 & 25,0 & 32,0 & 25,9 \\
Média & 26,7 & 26,7 & 30,7 & 31,0 \\
Variância & 3,28 & 8,74 & 62,50 & 7,96 \\
Desv. pad. & 1,81 & 2,96 & 7,91 & 2,82 \\
Coef. var. & 0,07 & 0,11 & 0,26 & 0,09 \\
\hline
\end{tabular}




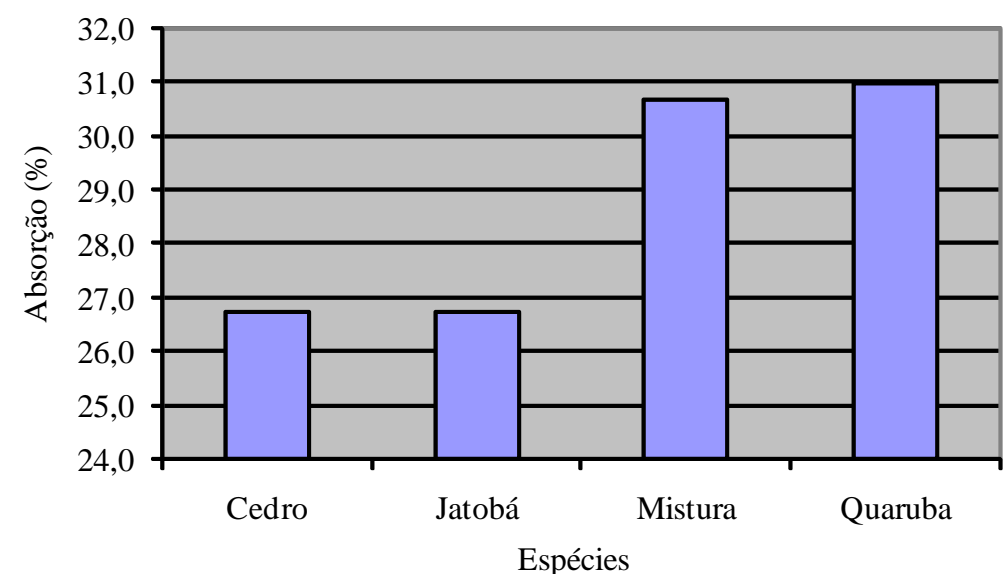

Figura 14 - Médias da absorção de água após 24 h

Os resultados dos ensaios de MOE e MOR são apresentados na Tabela 11 e nas Figuras 15 e 16.

Analisando os resultados das médias dos ensaios de flexão das chapas de cimento-madeira (Tabela 11 e Figuras 15 e 16), verifica-se que a direção dos corpos de prova na chapa influenciou nos valores do MOR e Módulo de Elasticidade MOE. Tanto na variável MOR como em MOE ocorreram diferenças estatísticas entre os valores médios. Para os valores de MOE, as espécies cedro e mistura apresentaram os maiores resultados na direção longitudinal à chapa, e para as espécies jatobá e quaruba, na direção transversal. Essa tendência não se repetiu para a variável MOR, em que as maiores médias na direção longitudinal foram as das chapas com resíduos de cedro e quaruba, e na direção transversal, jatobá e mistura. Essas diferenças podem ser explicadas pelo posicionamento dos corpos de prova nas chapas, onde a pressão aplicada pode variar em regiões próximo às bordas.
Os esforços na flexão estão relacionados mais com a compactação da chapa, propriamente dita, do que com a granulometria das partículas. Este, inclusive, pode ter sido o motivo para que a espécie jatobá não tenha apresentado valores de MOR estatisticamente superiores ou iguais as demais espécies, fato confirmado por Latorraca (2000) para a espécie Eucalyptus citriodora, que apresentou densidade maior que as outras espécies avaliadas. Por ter maior densidade, o jatobá apresentou uma razão de compactação mais baixa. Essa tendência não se repetiu nos ensaios de compressão paralela e tração perpendicular.

Nas propriedades mecânicas MOE e MOR, a espécie cedro apresentou valores médios superiores às demais. $\mathrm{O}$ valor de $\mathrm{MOE}$ de 7,2 GPa e o valor de MOR na direção transversal de 9,10 MPa são superiores ao valor estipulado no processo de fabricação de chapas de cimentomadeira (BISON..., 1978), que é de no mínimo 3 GPa para o MOE e de 9,00 MPa para o MOR. 
Tabela 11 - Resultados dos ensaios de MOE e MOR à flexão

\begin{tabular}{c|c|c|c|c|c|c|c|c}
\hline \multirow{2}{*}{ Corpos de prova } & \multicolumn{2}{|c|}{ Cedro } & \multicolumn{2}{c|}{ Jatobá } & \multicolumn{2}{c|}{ Quaruba } & \multicolumn{2}{c}{ Mistura } \\
\cline { 2 - 9 } & $\begin{array}{c}\text { MOE } \\
\text { (GPa) }\end{array}$ & $\begin{array}{c}\text { MOR } \\
\text { (MPa) }\end{array}$ & $\begin{array}{c}\text { MOE } \\
\text { (GPa) }\end{array}$ & $\begin{array}{c}\text { MOR } \\
\text { (MPa) }\end{array}$ & $\begin{array}{c}\text { MOE } \\
\text { (GPa) }\end{array}$ & $\begin{array}{c}\text { MOR } \\
\text { (MPa) }\end{array}$ & $\begin{array}{c}\text { MOE } \\
\text { (GPa) }\end{array}$ & $\begin{array}{c}\text { MOR } \\
\text { (MPa) }\end{array}$ \\
\hline 1 (A) & 8,87 & 9,39 & 3,70 & 3,41 & 4,87 & 8,01 & 5,53 & 6,64 \\
2 (A) & 11,53 & 10,72 & 6,29 & 4,18 & 5,71 & 8,47 & 7,07 & 7,31 \\
3 (A) & 8,10 & 8,98 & 5,18 & 3,28 & 3,47 & 7,37 & 5,79 & 5,98 \\
4 (A) & 7,56 & 9,35 & 5,13 & 2,13 & 4,77 & 7,80 & 4,67 & 4,32 \\
5 (A) & 8,38 & 10,75 & 6,04 & 4,89 & 6,26 & 7,92 & 7,03 & 4,98 \\
6 (A) & 5,16 & 6,22 & 4,81 & 4,27 & 5,07 & 6,95 & 3,80 & 4,32 \\
\hline Média A & 8,27 & 9,24 & 5,19 & 3,69 & 5,03 & 7,75 & 5,65 & 5,59 \\
Variância A & 4,24 & 2,74 & 0,86 & 0,94 & 0,90 & 0,28 & 1,67 & 1,56 \\
Desv. Pad. A & 2,06 & 1,65 & 0,93 & 0,97 & 0,95 & 0,53 & 1,29 & 1,25 \\
Coef. Var. A & 0,25 & 0,18 & 0,18 & 0,26 & 0,19 & 0,07 & 0,23 & $22 \%$ \\
\hline 1 (B) & 6,12 & 6,98 & 5,85 & 6,10 & 4,98 & 6,30 & 3,98 & 4,98 \\
2 (B) & 7,83 & 10,96 & 7,91 & 5,66 & 6,52 & 8,01 & 10,96 & 9,63 \\
3 (B) & 5,36 & 6,52 & 5,63 & 4,90 & 5,76 & 8,46 & 5,75 & 7,64 \\
4 (B) & 8,00 & 10,17 & 3,27 & 3,41 & 5,02 & 7,41 & 3,29 & 3,99 \\
5 (B) & 9,21 & 10,63 & 4,94 & 4,90 & 6,27 & 8,05 & 5,34 & 6,64 \\
6 (B) & 6,68 & 9,35 & 3,85 & 3,36 & 5,37 & 7,12 & 4,17 & 5,65 \\
\hline Média B & 7,20 & 9,10 & 5,24 & 4,72 & 5,65 & 7,56 & 5,58 & 6,42 \\
Variância B & 1,98 & 3,63 & 2,71 & 1,28 & 0,42 & 0,61 & 7,76 & 4,08 \\
Desv. Pad. B & 1,41 & 1,91 & 1,65 & 1,13 & 0,64 & 0,78 & 2,79 & 2,02 \\
Coef. Var B & 0,20 & 0,21 & 0,31 & 0,24 & 0,11 & 0,10 & 0,50 & $31 \%$ \\
\hline Média 12 & 7,73 & 9,17 & 5,22 & 4,21 & 5,34 & 7,66 & 5,62 & 6,01 \\
Variância 12 & 3,14 & 2,90 & 1,62 & 1,30 & 0,71 & 0,42 & 4,29 & 2,75 \\
Desv. Pad. 12 & 1,77 & 1,70 & 1,27 & 1,14 & 0,84 & 0,64 & 2,07 & 1,66 \\
Coef. Var. 12 & 0,23 & 0,19 & 0,24 & 0,27 & 0,16 & 0,08 & 0,37 & $28 \%$ \\
\hline
\end{tabular}

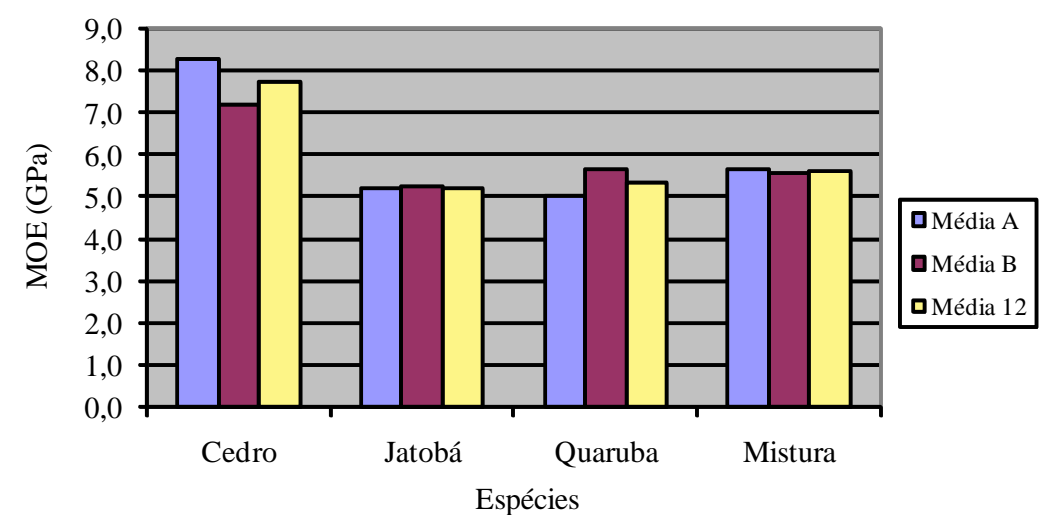

Figura 15 - Médias dos resultados de MOE 


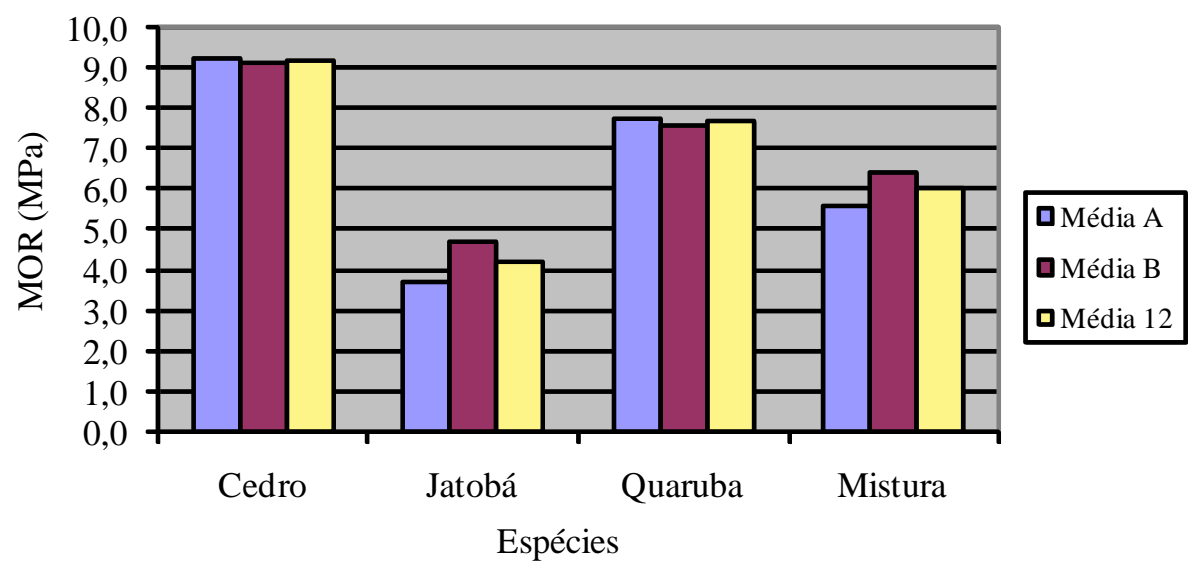

Figura 16 - Médias dos resultados de MOR

Tabela 12 - Resultados dos ensaios de tração perpendicular

\begin{tabular}{c|c|c|c|c}
\hline \multirow{2}{*}{ Corpos de prova } & \multicolumn{4}{|c}{ Resistência à tração perpendicular (MPa) } \\
\cline { 2 - 5 } & Cedro & Jatobá & Quaruba & Mistura \\
\hline $1(\mathrm{~A})$ & 1,35 & 1,72 & 0,91 & 1,31 \\
\hline $2(\mathrm{~A})$ & 1,60 & 1,11 & 1,02 & 1,37 \\
\hline $3(\mathrm{~A})$ & 1,92 & 1,78 & 1,93 & 1,2 \\
\hline $4(\mathrm{~A})$ & 1,54 & 1,19 & 1,54 & 1,38 \\
\hline $1(\mathrm{~B})$ & 1,42 & 1,46 & 0,89 & 1,06 \\
\hline $2(\mathrm{~B})$ & 1,52 & 1,83 & 1,19 & 1,24 \\
\hline 3 (B) & 1,70 & 1,8 & 1,86 & 0,88 \\
\hline $4(\mathrm{~B})$ & 1,71 & 1,37 & 1,48 & 1,08 \\
\hline Média & 1,60 & 1,53 & 1,35 & 1,19 \\
\hline Variância & 0,03 & 0,08 & 0,17 & 0,03 \\
\hline Desv. Pad. & 0,18 & 0,29 & 0,41 & 0,17 \\
\hline Coef. Var. & $11 \%$ & $19 \%$ & $30 \%$ & $15 \%$ \\
\hline
\end{tabular}

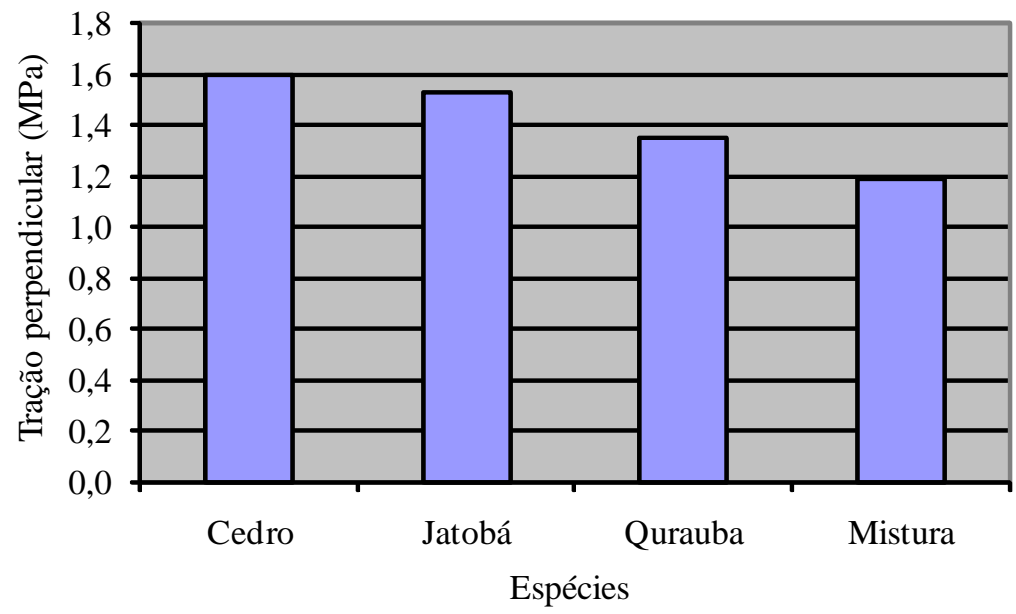

Figura 17 - Médias dos resultados de tração perpendicular

Os resultados dos ensaios de ligação interna ou tração perpendicular são apresentados na Tabela 12 e na Figura 17.

Esses resultados apontaram valores diferentes, variando de 1,19 MPa a 1,53 MPa. Os corpos de prova sofreram ruptura brusca, próximo à linha média da espessura, com a fratura da argamassa pela maior fragilidade em relação à tração, e imediatamente o rompimento das fibras de madeira. Esses resultados quando comparados às exigências mínimas do processo (BISON..., 1978), que é de 0,4 MPa, são considerados ótimos e 
superiores aos valores obtidos por Latorraca (2000) para a espécie Eucalyptus robusta, de 0,71 MPa, e de Okino et al. (2004) para a espécie Hevea brasiliensis Müll, de 0,41 MPa.

A Tabela 13 e a Figura 18 apresentam os resultados dos ensaios de compressão paralela.

No ensaio de compressão paralela (Tabela 13 e Figura 17), verificou-se o efeito produzido pela aplicação da pressão que influenciou no adensamento do compósito. O desempenho da espécie jatobá apresentou valores aproximadamente iguais ao ensaio de compressão axial, influenciado pela menor razão de compactação da chapa.
O compósito com resíduos de cedro, mistura e quaruba apresentou resultados superiores aos realizados nos ensaios de compressão axial na primeira fase, provavelmente pela aplicação da pressão de moldagem da chapa. O efeito mola dificulta o adensamento das espécies de menor massa específica, pelo maior volume de resíduos na moldagem de corpos de prova cilíndricos, que foram adensados manualmente com espátula. A aplicação de pressão reduz a quantidade de água, além de proporcionar melhor adesão entre as fases, pela redução de vazios.

Tabela 13 - Resultados dos ensaios de compressão

\begin{tabular}{c|c|c|c|c}
\hline \multirow{2}{*}{ Corpos de prova } & \multicolumn{4}{|c}{ Resistência (MPa) } \\
\cline { 2 - 5 } & Cedro & Jatobá & Quaruba & Mistura \\
\hline 1 (A) & 14,62 & 26,18 & 16,03 & 16,38 \\
2 (A) & 14,46 & 26,39 & 16,82 & 16,20 \\
3 (A) & 13,56 & 17,22 & 14,97 & 15,68 \\
4 (A) & 15,40 & 17,03 & 17,06 & 16,91 \\
1 (B) & 17,93 & 23,95 & 13,30 & 14,27 \\
2 (B) & 15,50 & 23,02 & 16,63 & 13,03 \\
3 (B) & 17,07 & 16,66 & 16,63 & 12,86 \\
4 (B) & 16,70 & 16,84 & 13,52 & 12,68 \\
Média & 15,66 & 20,91 & 15,62 & 14,75 \\
Variância & 2,18 & 19,26 & 2,28 & 3,05 \\
Desv. Pad. & 1,48 & 4,39 & 1,51 & 1,75 \\
Coef. Var. & $9 \%$ & $21 \%$ & $10 \%$ & $12 \%$ \\
\hline
\end{tabular}

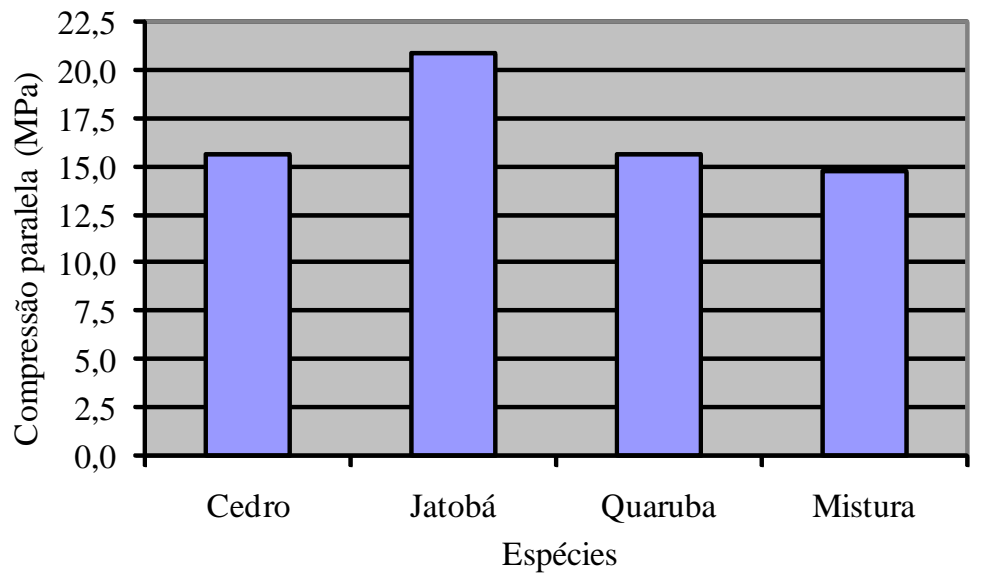

Figura 18 - Médias dos resultados de compressão 


\section{Conclusões}

Com base nos resultados dos ensaios conclui-se que:

(a) o uso de lavagem para as espécies estudadas não é considerado adequado para a produção de compósitos cimento-madeira;

(b) as espécies utilizadas como matéria-prima (dicotiledôneas) para a confecção de chapas de cimento-madeira deste estudo tiveram melhor desempenho quando utilizado o tratamento com aditivo acelerador de pega à base de cloreto de cálcio;

(c) de uma forma geral, o aumento da concentração de cloreto de cálcio de 3\% para 5\% melhora a compatibilidade do resíduo com a matriz cimentante, conduzindo a melhores resultados de resistência mecânica;

(d) a resistência à compressão axial mostrou ser um método eficiente para avaliar a compatibilidade entre o cimento e a madeira;

(e) as espécies cedro, jatobá e quaruba com uso de aditivo cloreto de cálcio a 5\% após a lavagem das amostras são as mais indicadas para fabricação de chapas de cimento-madeira entre as estudadas;

(f) as propriedades físicas e mecânicas das chapas são diretamente influenciadas por uma baixa razão de compactação atingida pelo compósito; e

(g) todas as chapas produzidas com as espécies estudadas (cedro, jatobá, quaruba e mistura) apresentaram características físicas e mecânicas adequadas, superando as especificações dos fabricantes, sendo consideradas adequadas para moldagem de chapas de cimento-madeira. A espécie cedro, entre as estudadas, apresentou os melhores resultados de propriedades físicas e mecânicas.

\section{Referências bibliográficas}

ASSOCIAÇÃO BRASILEIRA DE NORMAS TÉCNICAS. NBR 5733: cimento Portland de alta resistência inicial. Rio de Janeiro, 1991. 5 p.

ASSOCIAÇÃO BRASILEIRA DE NORMAS TÉCNICAS. NBR 5743: cimento Portland determinação da perda ao fogo. Rio de Janeiro, 1989. 3 p.

\section{ASSOCIAÇÃO BRASILEIRA DE NORMAS} TÉCNICAS. NBR 7215: cimento Portland: determinação da resistência à compressão. Rio de Janeiro, 1996. 8 p.
ASSOCIAÇÃO BRASILEIRA DE NORMAS TÉCNICAS. NBR 7217: agregados: determinação da composição granulométrica, método de ensaio. Rio de Janeiro, 1987a. 3p.

\section{ASSOCIAÇÃO BRASILEIRA DE NORMAS} TÉCNICAS. NBR 7251: agregado em estado solto: determinação da massa unitária, método de ensaio. Rio de Janeiro, 1982. 3 p.

ASSOCIAÇÃO BRASILEIRA DE NORMAS TÉCNICAS. NBR 9776: agregados: determinação da massa específica de agregados miúdos por meio do frasco de Chapman, método de ensaio. Rio de Janeiro, 1987b. 3 p.

ASSOCIAÇÃO BRASILEIRA DE NORMAS TÉCNICAS. NBR 9939: agregados: determinação do teor de umidade total, por secagem, em agregado graúdo. Rio de Janeiro, 1987c. 2 p. ASSOCIAÇÃO BRASILEIRA DE NORMAS TÉCNICAS. NBR 11579: cimento Portland: determinação da finura por meio da peneira $75 \mu \mathrm{m}$ ( $\mathrm{n}^{\circ}$ 200): método de ensaio. Rio de Janeiro, 1991a. 3 p.

\section{ASSOCIAÇÃO BRASILEIRA DE NORMAS}

TÉCNICAS. NBR 11582: cimento Portland: determinação da expansabilidade de Le Chatelier: método de ensaio. Rio de Janeiro, 1991b. 2 p.

ASSOCIAÇÃO BRASILEIRA DE NORMAS TÉCNICAS. NBR NM 11-2: cimento Portland: análise química: determinação de óxidos principais por complexometria: parte 2: método ABNT. Rio de Janeiro, 2009. 16 p.

ASSOCIAÇÃO BRASILEIRA DE NORMAS TÉCNICAS. NBR NM 13: cimento Portland: análise química: determinação de óxido de cálcio livre pelo etileno glicol. Rio de Janeiro, 2004a. 4 p.

ASSOCIAÇÃO BRASILEIRA DE NORMAS TÉCNICAS. NBR NM 16: cimento Portland: análise química: determinação de anidrido sulfúrico. Rio de Janeiro, 2004b. 3 p.

\section{ASSOCIAÇÃO BRASILEIRA DE NORMAS} TÉCNICAS. NBR NM 22: cimento Portland com adições de materiais pozolânicos: análise química: método de arbitragem. Rio de Janeiro, 2004c. 17 p.

\section{ASSOCIAÇÃO BRASILEIRA DE NORMAS TÉCNICAS. NBR NM 23: cimento portland:} determinação de massa específica. Rio de Janeiro, 1998a. 4 p.

ASSOCIAÇÃO BRASILEIRA DE NORMAS TÉCNICAS. NBR NM 43: cimento portland: determinação da pasta de consistência normal. Rio de Janeiro, 2003a. 8 p. 
ASSOCIAÇÃO BRASILEIRA DE NORMAS TÉCNICAS. NBR NM 65: cimento Portland: determinação do tempo de pega. Rio de Janeiro, 2003b. 4 p.

\section{ASSOCIAÇÃO BRASILEIRA DE NORMAS} TÉCNICAS. NBR NM 76: cimento Portland: determinação da finura pelo método de permeabilidade ao ar (Método de Blaine). Rio de Janeiro, 1998b. 12 p.

\section{AMERICAN SOCIETY FOR TESTING AND}

MATERIAL. ASTM D1037: standard methods for evaluating properties of wood-based fiber and particle panel materials. In: AMERICAN SOCIETY FOR TESTING AND MATERIAL. Annual Book of ASTM Standards. Philadelphia, 1996.

BATISTA, A. M. A Influência do Tratamento em Compósitos de Cimento-Madeira. Projeções, v. 19/20, p. 1-3, jan./dez. 2001/2002.

BERALDO, A. L. et al. Viabilidade de Fabricação de Compósitos Resíduos de Madeiras e Cimento Portland (CBC). In: WORKSHOP RECICLAGEM DE RESÍDUOS COMO MATERIAIS DE CONSTRUÇÃO CIVIL, 1996, São Paulo. Anais... São Paulo: ANTAC, 1996. p. 77-82.

BERALDO, A. L. et al. Compósitos à Base de Resíduos Vegetais e Cimento Portland. In: ENCONTRO BRASILEIRO EM MADEIRAS E EM ESTRUTURA DE MADEIRA, 8., Uberlândia, 2002. Anais... Uberlândia, 2002.

BERALDO, A. L.; CARVALHO J. V. Portland Cement: Eucalyptus grandis composite. Scientia Forestalis, Piracicaba, v. 65, p. 150-161, jun. 2004.

\section{BISON WOOD-CEMENT BOARD. Bison}

Report. [s.l:s.n], 1978. 10 p.

EUROPEAN COMMITTEE FOR

STANDARDIZATION. EUROPEAN

STANDARD. EN 310: particleboards and fiberboards: determination of modulus of elasticity in bending and bending strength. Bruxelas: 1993a.

\section{EUROPEAN COMMITTEE FOR}

STANDARDIZATION. EUROPEAN

STANDARD. EN 317: particleboards and fiberboards: determination of swelling in thickness after immersion in water. Bruxelas: 1993b.

\section{EUROPEAN COMMITTEE FOR}

STANDARDIZATION. EUROPEAN

STANDARD. EN 319: particleboards and fiberboards: determination of internal adhesion. Bruxelas: 1993c.
EUROPEAN COMMITTEE FOR STANDARDIZATION. EUROPEAN STANDARD. EN 322: particleboards and fiberboards: determination of humidity. Bruxelas: 1993d.

\section{EUROPEAN COMMITTEE FOR} STANDARDIZATION. EUROPEAN STANDARD. EN 323: particleboards and fiberboards: determination of density. Bruxelas: 1993e.

GEIMER, R.; SOUZA, M. R.; MOSLEMI, A. A. Low Density Cement-Bonded Wood Composites Made Conventionally and With Carbon Dioxide Injection. Drvna Industrija, v. 47, n. 2, p. 55-62, 1996.

GRANDI, L. A. C. Placas Pré-Moldadas de Argamassa de Cimento e Pó de Serra. 128 f. Campinas, 1995. Tese (Doutorado em Engenharia Agrícola). - Departamento de Construções Rurais, Faculdade de Engenharia Agrícola, Univesidade Estadual de Campinas, Campinas, 1995.

\section{LATORRACA, J. V. F. Eucalyptus spp. na} Produção de Painéis Cimento-Madeira. $182 \mathrm{f}$. Curitiba, 2000. Tese (Doutorado em Ciências Florestais) - Setor de Ciências Agrárias, Universidade Federal do Paraná, Curitiba, 2000.

LATORRACA, J. V.; IWAKIRI, S. Efeito da Cura a Vapor Sobre Propriedades Mecânicas de Painéis Cimento-Madeira. Floresta e Ambiente, v. 8, n. 1, p. 84-93, jan./dez. 2001.

LENTINI, M. et al. Fatos Florestais da Amazônia 2005. Belém: Instituto do Homem e Meio Ambiente da Amazônia, 2005. 140 p.

LIMA, A. M. Avalição de Tratamentos Físicos na Resistência à Compressão de Compósitos Cimento Madeira à Base de Resíduos de Serrarias da Zona Metropolitana de Belém. 150 f. Belém, 2005. Dissertação (Mestrado em Engenharia Civil) - Programa de Pós-Graduação em Engenharia Civil, Universidade Federal do Pará, Belém, 2005.

MENDES, L. M. et al. Eucalyptus spp. na Produção de Painéis OSB (Orientes Strand Board. In: ENCONTRO BRASILEIRO EM MADEIRAS E EM ESTRUTURAS DE MADEIRA, 9., Cuiabá, 2004. Anais... Cuiabá: , 2004.

MOSLEMI, A. A.; PFISTER, S. C. The Influence of Cement/Wood Ratio and Cement Type on Bending Strength and Dimensional Stability of Wood-Cement Composite Panels. Wood and Fiber Science, v. 19, n. 2, p. 165-175, 1987. 
OKINO, E. Y. A. et al. Chapa Aglomerada de Cimento-Madeira de Hevea brasiliensis Müll. Arg. Revista Árvore, Viçosa, MG, v. 28, n. 3, p 451457, 2004.

\section{PIMENTEL, L. L. Telhas Onduladas à Base de} Cimento Portland e Resíduos de Pinus caribaea. 67 f. São Paulo, 2000. Dissertação (Mestrado em Engenharia Agrícola) - Escola de Engenharia Agrícola, Universidade Estadual de Campinas, Campinas, São Paulo, 2000.

RAMÍREZ, S. C. S.; FREIRE, W. J. Tratamentos Aplicados ao Bagaço de Cana-de-Açúcar Visando Sua Utilização Para Fins de Material de Construção. In: WORKSHOP RECICLAGEM DE RESÍDUOS COMO MATERIAIS DE CONSTRUÇÃO CIVIL, São Paulo, 1996. Anais... São Paulo: ANTAC, 1996. p. 131-136.

SAVASTANO JUNIOR, H. Zona de Transição Entre Fibras e a Pasta de Cimento Portland: caracterização e inter-relação com as propriedades mecânicas do compósito. 209 f. São Paulo, 1992. Tese (Doutorado em Engenharia) - Escola Politécnica, Universidade de São Paulo, São Paulo, 1992.
SAVASTANO JUNIOR, H.; WARDEN, P. G.; COUTTS, R. S. P. Brazilian Waste Fibres as Reinforcement For Cement-Based Composites. Cement \& Concrete Composites, Kidlington, v. 22, n. 5, p. 379-384, 2000.

TEIXEIRA, D. E.; GUIMARÃES, T. L.

Tratamento de Partículas de Acácia mearnsii De Wild. Para Produção de Chapas de CimentoMadeira. Brasília: IBAMA; DIRPED; LPF, 1989. (Serie Técnica 11).

WOLFE, R. W.; GJINOLLI, A. Cement-Bonded Wood Composites as an Engineering Material: use of recycled wood and paper in building applications. 1997. Disponível em: <http://128.104.77.228/documnts/pdf1997/wolfe97 a.pdf>. Acesso em: 21 maio 2012.

ZHENGTIAN, L.; MOSLEMI, A. A. Influence of Chemical Additives on the Hydration Characteristics of Western Larch Wood-CementWater Mixtures. Forest Products Journal, v. 35, n. 7, p. 37-43, 1985.

\section{ZUCCO, L. L. Estudo da Viabilidade de} Fabricação de Placas de Compósitos à Base de Cimento e Casca de Arroz. 118 f. Campinas, 1999. Dissertação (Mestrado em Engenharia Agrícola) - Escola de Engenharia Agrícola, Universidade Estadual de Campinas, Campinas, 1999.

Revista Ambiente Construído

Associação Nacional de Tecnologia do Ambiente Construído

Av. Osvaldo Aranha, 99 - 3o andar, Centro

Porto Alegre - RS - Brasil CEP $90035-190$

Telefone: +55 (51) 3308-4084 Fax: +55 (51) 3308-4054

www. seer. ufrgs. br/ ambienteconstruido

E-mail: ambienteconstruido@ufrgs.br

150 Macêdo, A. N.; Costa e Souza, A. A.; Pompeu Neto, B. B. 